\title{
POST-MORTEM RESTORATIONS IN ANCIENT EGYPTIAN ANIMAL MUMMIES USING IMAGING
}

\author{
Stephanie D. Atherton-Woolham, Lidija M. McKnight \\ KNH Centre for Biomedical Egyptology, Faculty of Life Sciences, \\ The University of Manchester, Manchester, UK
}

\begin{abstract}
Animal mummy bundles in museum collections are evaluated through the application of imaging and are categorised as true, those containing skeletal remains, and pseudo, those containing non-skeletal remains. True mummies exhibited a variety of compositions, and frequently contained less than one complete individual despite the external appearance; an explanation for which has been ancient forgery. The analysis of animal mummy bundles in the Ancient Egyptian Animal Bio Bank, University of Manchester, suggested that in some instances this explanation may be inaccurate. This paper discusses nine mummy bundles, which displayed a variety of post-mortem modifications interpreted in two ways: the necessity for physical completion and the concept of the mummy bundle (rather than the content) as the primary representation of the deceased.
\end{abstract}

Keywords: animal mummy, post-mortem restorations, imaging

\section{INTRODUCTION}

One of the earliest applications of imaging was the investigation of mummified animal remains $(3,7)$. The continued use of imaging furthered the field of mummy studies in a non-invasive manner, including the identification and classification of ancient Egyptian animal mummy bundles (2, 4, 8, 11). Recent research by the authors reclassified these bundles as true, those containing skeletal remains, and pseudo, those containing non-skeletal remains (10). 
True mummy bundles comprised many different compositions and were regularly composed of multiple individuals or less than one complete, articulated individual. In addition, the inclusion of detached skeletal material, not always of the same species as the primary individual, was also highlighted. Non-skeletal remains were often included within bundles alongside skeletal remains to provide shape and stability.

Current explanations for such composite mummy bundles have justified them as 'budget votive offerings' created to dupe pilgrims into purchasing a product that did not fit the external description (5). This paper describes two alternative thought processes behind animal mummification: the necessity for physical completion and the idea of the mummy bundle (rather than the content) as the primary representation of the deceased.

\section{MATERIALS AND METHODS}

The study group comprised nine animal mummies (macroscopically identified as three crocodile mummies and six bird mummies) from seven museum collections in the UK and USA identified through the Ancient Egyptian Animal Bio Bank, University of Manchester (9) (Table 1). All were subjected to imaging: radiography, either plain film (XR), computed (CR) or digital (DR), dependent upon the equipment available at the time in the clinical setting. In addition, four mummy bundles were subjected to computed tomography (CT) in tandem with radiography (Table 1 ).

Table 1. Details of the mummy bundles under investigation and imaging parameters employed

\begin{tabular}{llll}
\hline $\begin{array}{l}\text { AEABB } \\
\text { Reference }\end{array}$ & Holding Institution & $\begin{array}{l}\text { External Identi- } \\
\text { fication }\end{array}$ & Radiographic Specifications \\
\hline AEABB071 & $\begin{array}{l}\text { Manchester } \\
\text { Museum }\end{array}$ & $\begin{array}{l}\text { Crocodile } \\
\text { Mummy }\end{array}$ & $\begin{array}{l}\text { DR and CT (2011): Manchester } \\
\text { Royal Infirmary }\end{array}$ \\
\hline AEABB093 & Bolton Museum & Bird Mummy & XR (2000): University of York \\
\hline AEABB095 & Bolton Museum & Bird Mummy & XR (2000): University of York \\
\hline AEABB137 & $\begin{array}{l}\text { Touchstones, } \\
\text { Rochdale }\end{array}$ & $\begin{array}{l}\text { Crocodile } \\
\text { Mummy }\end{array}$ & $\begin{array}{l}\text { DR and CT (2011): Manchester } \\
\text { Royal Infirmary }\end{array}$ \\
\hline AEABB140 & $\begin{array}{l}\text { Touchstones, } \\
\text { Rochdale }\end{array}$ & $\begin{array}{l}\text { Crocodile } \\
\text { Mummy }\end{array}$ & $\begin{array}{l}\text { DR and CT (2011): Manchester } \\
\text { Royal Infirmary }\end{array}$ \\
\hline AEABB153 & $\begin{array}{l}\text { Royal Albert } \\
\text { Memorial Museum, } \\
\text { Exeter }\end{array}$ & Bird Mummy & $\begin{array}{l}\text { DR and CT (2011): Manchester } \\
\text { Royal Infirmary }\end{array}$ \\
\hline
\end{tabular}


Table 1. Continuation

\begin{tabular}{llll}
\hline $\begin{array}{l}\text { AEABB } \\
\text { Reference }\end{array}$ & Holding Institution & $\begin{array}{l}\text { External Identi- } \\
\text { fication }\end{array}$ & Radiographic Specifications \\
\hline AEABB393 & $\begin{array}{l}\text { Museum of Fine } \\
\text { Arts, Boston, USA }\end{array}$ & Bird Mummy & $\begin{array}{l}\text { XR (1988): Brigham and Women's } \\
\text { General Hospital, Boston, } \\
\text { Massachusetts }\end{array}$ \\
\hline AEABB527 & $\begin{array}{l}\text { Natural History } \\
\text { Museum, Tring }\end{array}$ & Bird Mummy & XR (2000): NHM, Tring \\
\hline AEABB550 & $\begin{array}{l}\text { Natural History } \\
\text { Museum, Tring }\end{array}$ & Bird Mummy & XR (2000): NHM, Tring \\
\hline
\end{tabular}

\section{RESULTS}

Post-mortem restorations within the study group, identified through imaging, were categorised in four types:

\section{Type One - inclusion of 1+ incomplete individuals}

Three mummy bundles exhibited type one post-mortem restorations. AEABB071 was externally identified as a crocodile mummy bundle with modelled eyes and a square lozenge design on the upper aspect of the body. Imaging demonstrated the remains of four Crocodylus niloticus (Nile crocodile) crania placed longitudinally, in addition to a complete juvenile Crocodylus niloticus (Nile crocodile) placed above the crania. Two radiopaque anomalies, consistent in size and shape with eggshell, were also highlighted. Reed placed longitudinally provided rigidity to the shape of the bundle (Fig. 1).
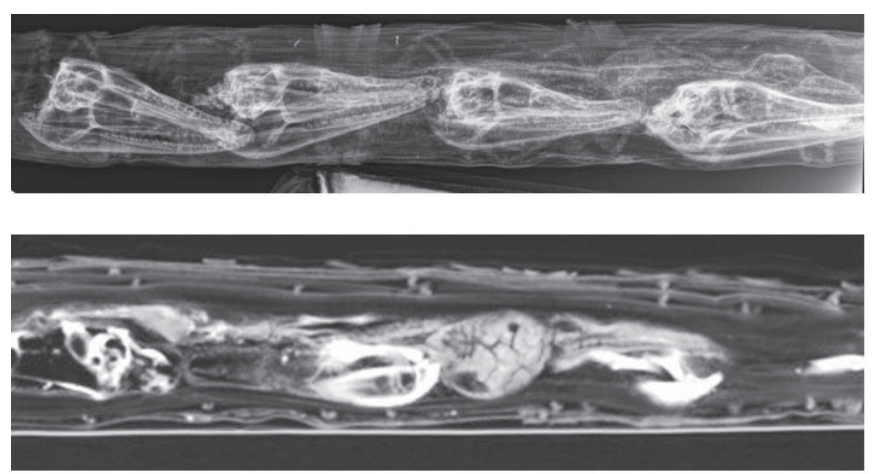

Figure 1. Imaging (DR and CT) of AEABB071, which contained four Crocodylus niloticus (Nile crocodile) crania, a single juvenile Crocodylus niloticus (Nile crocodile) and

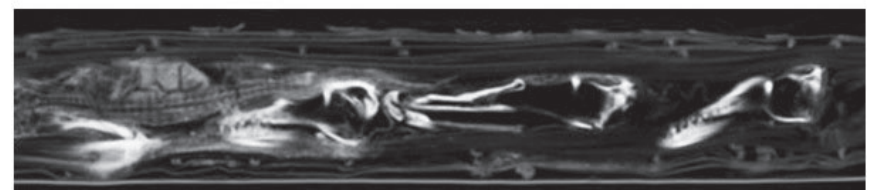
two anomalies thought to be eggshell. Image courtesy The Ancient Egyptian Animal Bio Bank / The Manchester Museum, UK. 
AEABB153 was identified macroscopically as a bird of prey with a square lozenge design on the upper aspect of the body. DR revealed that the body contained the post-cranial remains of a single, small Falconiforme (bird of prey), of which the left leg was absent following a mid-shaft amputation of the right tarsometatarsus. The head and beak of the mummy bundle were modelled from linen and a radiodense substance, likely to have been resinous in origin. CT demonstrated that the vertebrae of the post-cranial remains extended into the head of the bundle, in addition to separate vertebrae thought to be from a second, larger individual (Fig. 2).
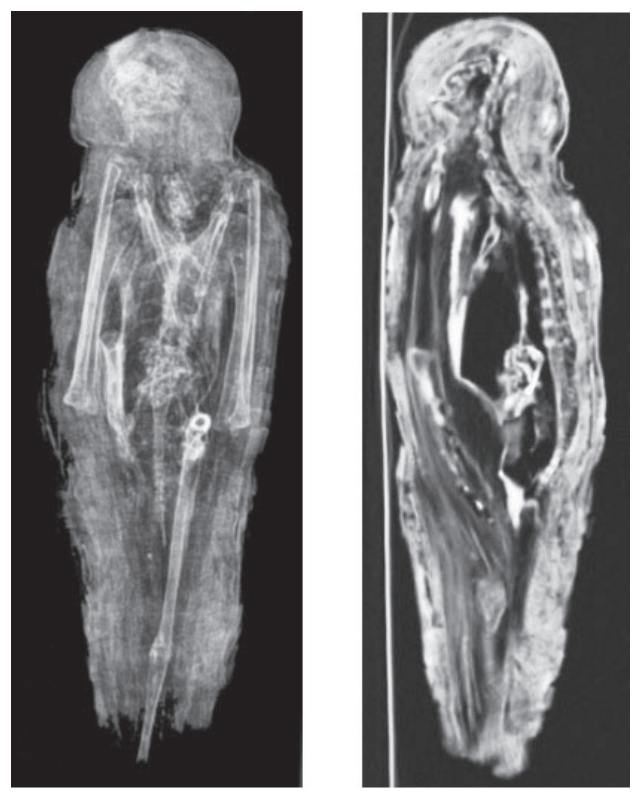

Figure 2. Imaging (DR and CT) of $A E A B B 153$, which contained two individuals, one identifiable as a small Falconiforme (bird of prey), which had suffered decapitation and post-cranial amputation to both lower limbs. Image courtesy The Ancient Egyptian Animal Bio Bank / The Royal Albert Memorial Museum, UK.

AEABB527 was externally identified as an ibis mummy bundle which contained the decapitated body of Milvus milvus/migrans (Red Kite/Black Kite) in the upper aspect. The fragmented remains of other avian species including a Threskiornithidae (large wading bird) species and a small Falconidae/Accipitridae (Falcon/Hawk) species were located at the distal end of the mummy bundle (Fig. 3). 


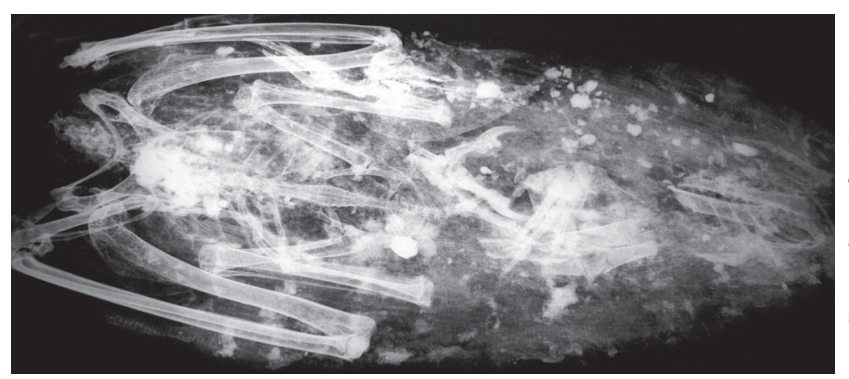

Figure 3. Imaging (XR) of AEABB527, which contained a single Milvus milvus/migrans (Red Kite/ Black Kite) alongside the fragmented remains of a Threskiornithidae (large wading bird) and a small Falconidae/Accipitridae

(Falcon/Hawk) species. Image courtesy The Ancient Egyptian Animal Bio Bank / The Trustees of the Natural History Museum, UK.

\section{Type Two - inclusion of an incomplete individual with a complete individual} Two bird mummy bundles (AEABB095 and AEABB550) exhibited type two post-mortem restorations. The primary individual in both bundles was a complete and fully articulated small bird of prey: Falco naumanni (Lesser Kestrel) (AEABB095) and Accipiter nisus/brevipes (Eurasian Sparrowhawk/Levant Sparrowhawk) (AEABB550) with a second individual placed across the breastbone of the primary individual. AEABB095 contained the post-abdominal remains of a small Crocodylus niloticus (Nile crocodile); whereas AEABB550 contained the wing of an additional individual, thought to have been another small Accipitridae (Hawk) (Fig. 4).
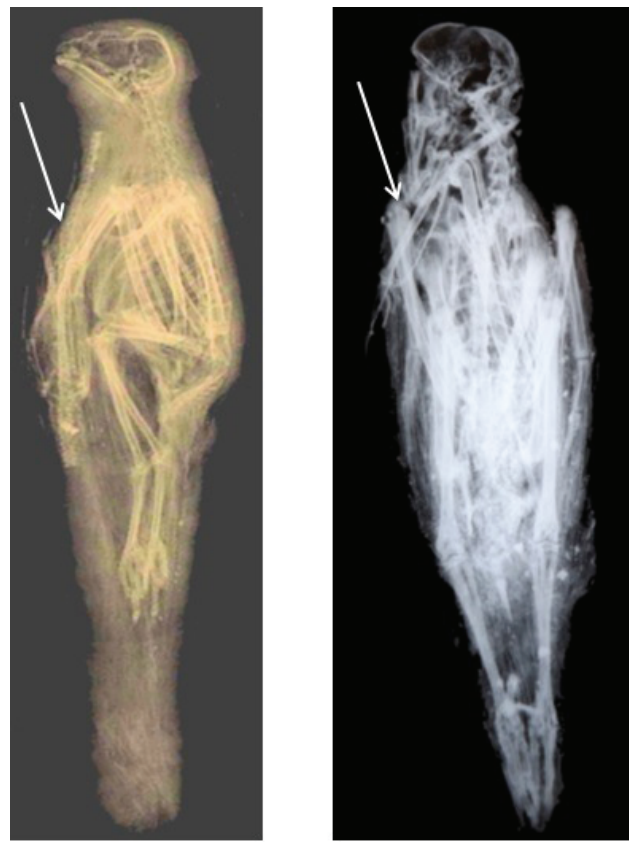

Figure 4. Imaging (XR) of AEABB095 and AEABB550 demonstrated two complete avian individuals - Falco naumanni (Lesser Kestrel) and Accipiter nisus / brevipes (Eurasian Sparrowhawk / Levant Sparrowhawk), respectively. AEABB095 also contained the remains of a Crocodylus niloticus (Nile crocodile), whereas AEABB550 contained an additional Accipitridae (Hawk) wing, both placed over the breastbone. Image courtesy The Ancient Egyptian Animal Bio Bank / Bolton Museum and Art Gallery / The Trustees of the Natural History Museum, UK. 


\section{Type Three - inclusion of non-skeletal remains with incomplete individuals}

Two crocodile mummy bundles (AEABB137 and AEABB140) exhibited type three post-mortem restorations. Neither bundle displayed any form of external decoration. The form of the bundles was provided by reed, which created the length required for a crocodilian shape, in addition to a single vertebra (AEABB137) and a single osteoderm (AEABB140), both identified as Crocodylus niloticus (Nile crocodile), placed in the mid-section of the bundles (Fig. 5).
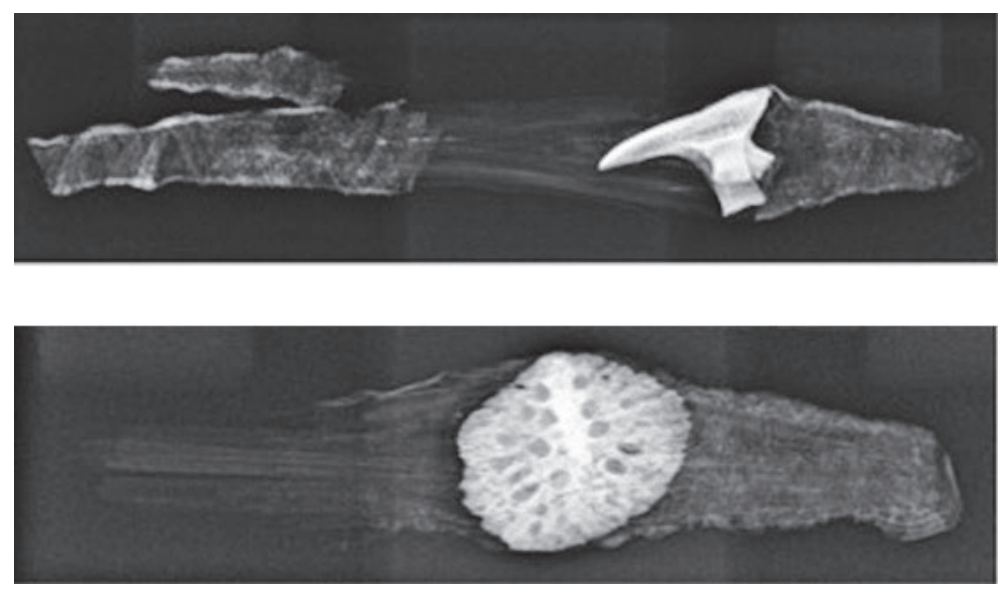

Figure 5. Imaging (DR and CT) of AEABB137 and AEABB140 highlighted the remains of a single vertebra (AEABB137) and a single osteoderm (AEABB140), both identified as Crocodylus niloticus (Nile crocodile) contained within a wrapped bundle of reeds, which created the length and form of the bundle. Image courtesy The Ancient Egyptian Animal Bio Bank / Touchstones Museum, Rochdale, UK.

\section{Type Four - replacement of detached body parts}

Two bird mummy bundles (AEABB093 and AEABB393) exhibited type four post-mortem restorations. AEABB093, identified as a Falco tinnunculus (Kestrel), showed that the right tarsometatarsus was fractured but remained articulated to the leg, although the left tarsometatarsus was amputated mid-shaft and replaced in the opposing anatomical position in the lower abdominal region of the mummy bundle. AEABB393, identified as a small Falconiforme (bird of prey), showed both tarsometatarsii were amputated and replaced in the opposite anatomical position at the distal end of the mummified remains (Fig. 6). 

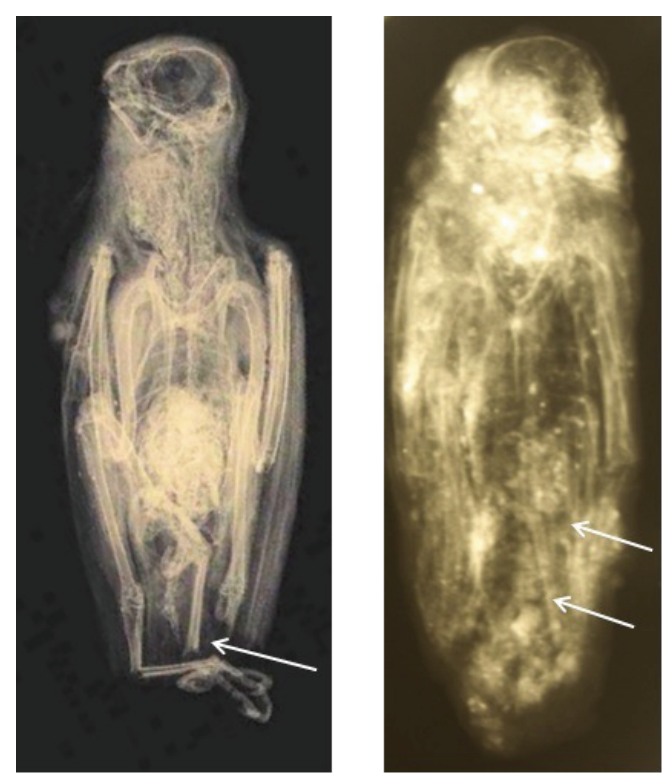

Figure 6. Imaging (XR) of AEABB093 and $A E A B B 393$ demonstrated two avian individuals: a Falco tinnunculus (Kestrel) and a small Falconiforme (bird of prey), respectively. Both had amputations in the lower limbs, which were subsequently replaced in the opposing anatomical position. Image courtesy The Ancient Egyptian Animal Bio Bank / Bolton Museum and Art Gallery, UK / Museum of Fine Arts, Boston, USA.

Photograph copyright 2014, Museum of Fine Arts, Boston.

\section{DISCUSSION.}

Interpretations concerning the use of isolated body parts from different individuals, as seen in types one and two, were thought to have been the result of partial disarticulation and fragmentation prior to mummification rites and practices. Rearing grounds within the liminal spaces of temple enclosures, such as at Saqqara and Tuna el-Gebel, would have offered a proportion of natural casualties and predeceased individuals. These mummies resulted from such areas being considered part of the sacred landscape in which a temple was located. Therefore, any creature that died within this area was worthy of mummification, burial and rejuvenation $(6,14)$. Indeed, literary evidence attests to the collection and mummification of deceased animals found within the sacred boundaries at Saqqara (12). This further demonstrated that the ancient Egyptians viewed the death and selection of animals for mummification in a similar context to the Osiris Myth. This highlighted that death, for both humans and animals, was considered a process of dismemberment, collection and 'piecing together' of the physical elements of the individual. The creation of a mummy bundle provided the means by which an image represented the deceased and thus enabled rejuvenation (1).

The primary purpose of the mummy bundle, alongside other funerary images, was to provide the spiritual elements of the deceased with a perfect image of the body in which they could reside, in the event that the mummified body became damaged or unrecognisable (13). AEABB137 and AEABB140 
may be explained by this concept. The mummy bundles were crocodilian in shape with the use of reed to create the length and contained only an isolated skeletal element. Therefore, the mummy bundle replaced the content as the image of the deceased.

Types two and four post-mortem restorations could be considered attempts at maintaining a complete individual. The type two mummy bundles contained a complete with an incomplete individual and were perhaps an attempt to provide some context for the incomplete individual. The type four mummy bundles were likely to have occurred during the mummification process, perhaps the result of less than careful handling process, which was later rectified prior to wrapping. The concept of collection and piecing together the physical parts of the body were further represented in these mummy bundles.

Imaging revealed that a number of mummy bundles contained highly fragmented, unidentifiable content. The authors believe these should also be considered a form of post-mortem restoration as they indicated the collection and re-amalgamation of skeletal remains with the ultimate intention of creating a mummy bundle worthy of rejuvenation. Further imaging, particularly through the use of micro-CT and 3D printing, will hopefully permit improved visualisation, therefore allowing the concept of post-mortem restorations in animal mummies to be investigated in more detail.

\section{ACKNOWLEDGEMENTS}

The authors would like to thank the participating museums for allowing their collections to be incorporated into the Ancient Egyptian Animal Bio Bank for research purposes. Thanks are also extended to the University of York and Manchester Royal Infirmary for use of their imaging equipment and expertise, in particular to Prof. Judith Adams and the radiographers. Access to equipment was granted through the Research Endowment at Central Manchester University Hospitals NHS Foundation Trust. The Kay Hinckley Trust and Leverhulme Trust (RPG-2013-143) are also thanked for funding animal mummy research at the University of Manchester.

\section{REFERENCES}

1. Assmann J. (2005). Death and Salvation in Ancient Egypt. Translated from the German by D. Lorton. Cornell University Press. Ithaca and London.

2. Atherton S.D. (2012). An investigation of the post-mortem status and mummification practices of avian votive mummies in ancient Egypt. Unpublished $\mathrm{PhD}$ Thesis, University of Manchester. 
3. Holland T. (1937). X-rays in 1896. Journal of Liverpool Medico-Chirurgical Society, 45, 61.

4. Ikram S., Iskander N. (2002). Catalogue Général of Egyptian Antiquities in the Cairo Museum Nos. 24048-24056; 29504-29903 (selected); 51084-51101; 61089 Non-Human Mummies. The Supreme Council of Antiquities Press. Cairo.

5. Ikram S. (2005) (ed.). Divine Creatures: Animal mummies in ancient Egypt. American University in Cairo Press. Cairo.

6. Kessler D., Nur el-Din A. (2005). Tuna el-Gebel: Millions of ibises and other animals. In: S. Ikram (ed.), Divine Creatures: Animal mummies in ancient Egypt. American University in Cairo Press. Cairo. 120-163.

7. König W. (1896). 14 photographien von Röntgen-Stahlen. Verlag von Johann Ambrosius Barth. Leipzig.

8. McKnight L.M. (2010). Imaging applied to animal mummification in ancient Egypt. BAR Series 2175. Archaeopress. Oxford.

9. McKnight L.M., Atherton S.D., David A.R. (2011). Introducing the Ancient Egyptian Animal Bio Bank at the KNH Centre for Biomedical Egyptology, University of Manchester. Antiquity Project Gallery, 85, 329.

10. McKnight L. M., Atherton S. D. (2014). How to 'pigeon-hole' your animal mummy - a proposed categorisation system for ancient Egyptian wrapped animal remains based on radiographic evaluation. Yrbk Mummy Studies, 2, 109-116.

11. Raven M., Taconis W.K.E. (2005). Egyptian Mummies: radiological atlas of the collections in the National Museum of Antiquities at Leiden. Brepols Publisher. Turnhout.

12. Ray J.D. (2011). Texts from the Baboon and Falcon Galleries: Demotic, Hieroglyphic and Greek Inscriptions from the Sacred Animal Necropolis, North Saqqara. Egypt Exploration Society. London.

13. Taylor J.H. (2001). Death and the Afterlife in ancient Egypt. British Museum Press. London.

14. Von den Driesch A., Berteaux V., Kessler D., Peters J., Steinmann F. (2006). Mummified, deified and buried at Hermopolis Magna - the sacred birds from Tuna el-Gebel, Middle Egypt. Ägypten und Levante, 15, 203-244.

\section{Address for correspondence:}

Dr Stephanie D. Atherton-Woolham

KNH Centre for Biomedical Egyptology

Faculty of Life Sciences

The University of Manchester

Oxford Road, Manchester M13 9PT, UK

E-mail: stephanie.atherton@manchester.ac.uk 